\title{
ASPECTOS DO SETOR SAÚDE - PARTICIPAÇĀO DO ENFERMEIRO *
}

\author{
* * Arilda de São Sabbas Pucú \\ * * Marta Cavalcanti Teixeira
}

\begin{tabular}{l|l|} 
& $\mathrm{RBEn} / 03$ \\
\hline
\end{tabular}

PUCÚ, A.S.S., TEIXEIRA, M.C. - Aspectos do setor saúde-participação do enfermeiro. Rev. Bras. Enf.; DF, 32 : 375-384, 1979.

\section{I - INTRODUÇAOO}

Há vários anos, profissionais ligados ao setor de saúde, vêm abordando e estudando questões relativas às formas de prestação de assistência que atentem para a situação de morbimortalidade e sejam condizentes com o contexto sócio-econômico-cultural do país.

Nesse sentido, foram analisados e destacados aspectos como:

- a racionalização de recursos físicos, materiais e humanos;

- a necessidade de prestação de assistência, maximizando a eficiência e eficácia;

- o aumento de cobertura da assistência básica às populações rurais e periféricas dos grandes centros urbanos;

- a delegaçāo de funções ao pessoal técnico e auxiliar.

Essas são as premissas básicas de modelos assistenciais que, sob a forma de programas, foram apresentadas como propostas alternativas e inovadoras para reestruturação do sistema de saúde. Inicialmente, estas questỏes permaneceram a nível de estudos e debates; e as tentativas de operacionalização dos modelos se restringiram a programas de algumas Instituiões e Universidades, em caráter experimental e, pois, com pequena abrangência. Uma série de fatores políticos conjunturais conjugados à falta de soluções para a crise do setor, caracterizada pelo volume dos recursos financeiros alocados para o setor saúde, sem a devida correspondência da melhoria do nível de saúde da população, obrigou a modificações significativas.

A partir do II P.N.D. (1975-1979) e da $\mathrm{V}$ Conferência Nacional de Saúde (1975), caracterizou-se a necessidade de alterações do política de saúde vigente. Redefiniram-se formas de prestação de assistência, prioridades, custos e investimentos etc. Desde então a criação de instrumentos legais favoreceram aque-

- Tema Livre - XXXI CBFn - Fortaleza - Ceará - 1979.

* Enfermeiras do INAMPS - RJ. 
PUCU, A.S.S., TELXIIRA, M.C. - Aspectos do setor saúde-participaçăo do enfermeiro.

Rev. Bras. Enf.; DF, 32 : 375-384, 1979.

las tendências e impulsionaram a absorção, pelas Instituições, dos programas de extensão de cobertura e dos projetos de regionalização.

Os instrumentos legais foram:

- Lei n.o 6.229 (Sistema Nacional de Saúde-1975);

- Decreto de criação do PIASS (1976);

- Portaria Ministerial 001 (MPAS/ MS-1978)

Na implantação do programa de saúde, verifica-se, ainda, a existência de uma gama de problemas, tais como:

- organização global e setorial;

- racionalização dos recursos financeiros, físicos e materiais;

- produção e utilização de medicamentos;

- a questão de recursos humanos, cujas soluções estão na dependência de definição efetiva dentro da política de saúde, quanto à viabilização destes modelos como estratégicos e fundamentais para o setor. Mesmo assim é considerável trazer como elementos para discussão, peculiaridades que envolvam a participação do enfermeiro, um dos recursos humanos envolvidos.

Este trabalho pretende situar o enfermeiro, ressaltar a importância de seu papel na análise e debate das questōes significativas para a viabilização dos novos modelos assistenciais propostos e, também, situar a problemática relativa à sua inserção nesta fase de modificações do Setor Saúáe.

\section{II - PROGRAMAS E PROJETOS PARA O SETOR SAÚDE}

O esgotamento do modelo assistencial vem se intensificando na medida em que se avolumam as necessidades não satisfeitas da população e a elevação dos custos vai consumindo vorazmente os recursos financeiros destinados ao Setor Saúde.

Assim sendo, impõe-se a busca de modelos alternativos que recuperem sua competência frente à realidade atual. As propostas políticas visam a integração de diferentes setores, como: saúde, saneamento, educação e habitação, além de outros diretamente envolvidos no sistema produtivo.

Somente a partir de 1974, em decorrência da necessidade de reciclagem do modelo econômico, fol que a adequação do sistema de saúde às suas novas responsabilidades, veio a se constituir objeto de preocupação do governo federal (1).

Como saída para a crise do sistema de saúde, começaram a surgir proposiçōes visando superar o impasse. Tais propostas e iniciativas, a princípio de caráter experimental, foram promovidas por Secretarias de Saúde, em convênio com Universidades e outras Instituições, não só nacionais como até internacionais, voltadas para o desenvolvimento de modelos de serviços destinados às populações rurais. Os programas existentes apresentam grande preocupação com a implantação do Sistema Nacional de Saúde. Eles têm em vista a extensão de cobertura e/ou regionalização dos serviços de saúde.

A viabilização da extensão de cobertura tem vários problemas, ainda, sem solução, nas áreas de recursos humanos, equipamentos, medicamentos, organização, financiamento, ideologia e política de saúde.

"Os conceitos fundamentais do programa de extensão de cobertura são:

1 - Universalização do direito a proteção e à recuperação da saúde, assegurada principalmente às populações desassistidas;

2 - Oferta e produção ativa de serviços de saúde à população, de acordo com suas necessidades;

3 - Garantia de acessibilidade espacial da população aos serviços;

4 - Prioridade a controle dos problemas mais freqüentes nas áreas de saúde, nutrição e seneamento; 
PUCU, A.S.S., THXIRA, M.C. - Aspectos do setor saúde-participaçáo do enfermeiro.

Rov. Bras. Enf.; DF, 32 : 375-384, 1979.

5 - Responsabilidade do Estado na deflagração e na condução do processo;

6 - Estimulo à participação ampla da comunidade em todas as fases do processo, desde a programação;

7 - Utilização, em massa, de pessoal de nivel médio e elementar, atuando por delegação de funçōes mediante treinamento e supervisāo;

8 - Adoção de tecnologias simplificadas e de baixo custo;

9 - Utilização de equipamentos simplificados, instalados em unidades sanitárias localizadas de acordo com a dispersāo populacional;

10 - Organização das unidades de saúde num sistema de serviços hierarquizados e regionalizados, segundo o gráu de complexidade de cada uma, acompanhando a distribuição espacial da população". (2)

Entre os atuais programas de extensão de cobertura, o de maior abrangência é possivelmente o PIASS (Programa de Interiorizaçāo das Açōes de Saúde e Saneamento), localizado no Nordeste, voltado para as áreas rurais principalmente onde há ausência de órgãos prestadores de serviços assistenciais.

O componente fundamental é a criaçāo e implantação de MódulosBásicos constituídos por: Centro de Saúde, situado na sede do Município, uma rede de Postos de Saúde, localizados nos respectivos distritos, vilas e povoados da zona rural.

Propōe-se que os Módulos além de manterem Integração funcional entre sua unidades, busquem relaçōes de articulaçāo com outras Instituiçōes prestadoras de serviços assistenciais, assim como com outras formas nāo institucionais, como sejam as práticas comunitárias; apolem e mesmo incorporem alguns elementos da chamada medicina popular para que disto resultem maior beneficio à população.
Outra proposta de grande significado é a do Plano de Localização de Unidades de Serviço - PLUS - que, embora ainda não operacionalizado, foi a base teórica para a implantação do Programa da Prefeitura Municipal de Campinas (SP). Enfoca a regionalização e a extensão de cobertura às populaçōes urbana e periférica das grandes regiōes metropolitanas do país.

As diretrizes gerais do modelo de regionalizaçāo visam:

1 - Dar prioridade e intensificar as atividades de saúde que proporcionem maiores beneficios por mais balxo custo;

2 - A racionalização dos recursos físicos, humanos e materiais existentes;

3 - Atender às necessidades reais da população;

4 - A hierarquização de serviços em gráu de complexidade crescente;

5 - A integração de atividades prestadas por Instituiçōes de saúde e a universalização da assistência à saúde.

No quadro geral (I) dos programas de extensāo de cobertura, os acima citados sāo originários do setor saúde, enquanto outros, como por exemplo o POLONORDESTE, tem como finalidade o desenvolvimento sócio-econômico regional, incorporado conseqüentemente atividades de assistência, sugeridas nas propostas de extensāo de cobertura.

Outros programas com base na assistência primária existem isoladamente por serem desenvolvidos a nível municipal, como exemplo, os da Secretaria Municipal de Londrina, Niterói e Campinas.

Cabe resaltar que, segundo Relatório-78, da Prefeitura Municipal de Londrina, do total de atendimentos realizados, $86,4 \%$ foi resolvido e/ou controlado pelo auxiliar de saúde (Quadro II). 
PUCU, A.S.S., THXITRA, M.C. - Aspectos do setor saúde-participaçăo do enfermeiro. Rev. Bras. En?; DF, 32 : 375-384, 1979.

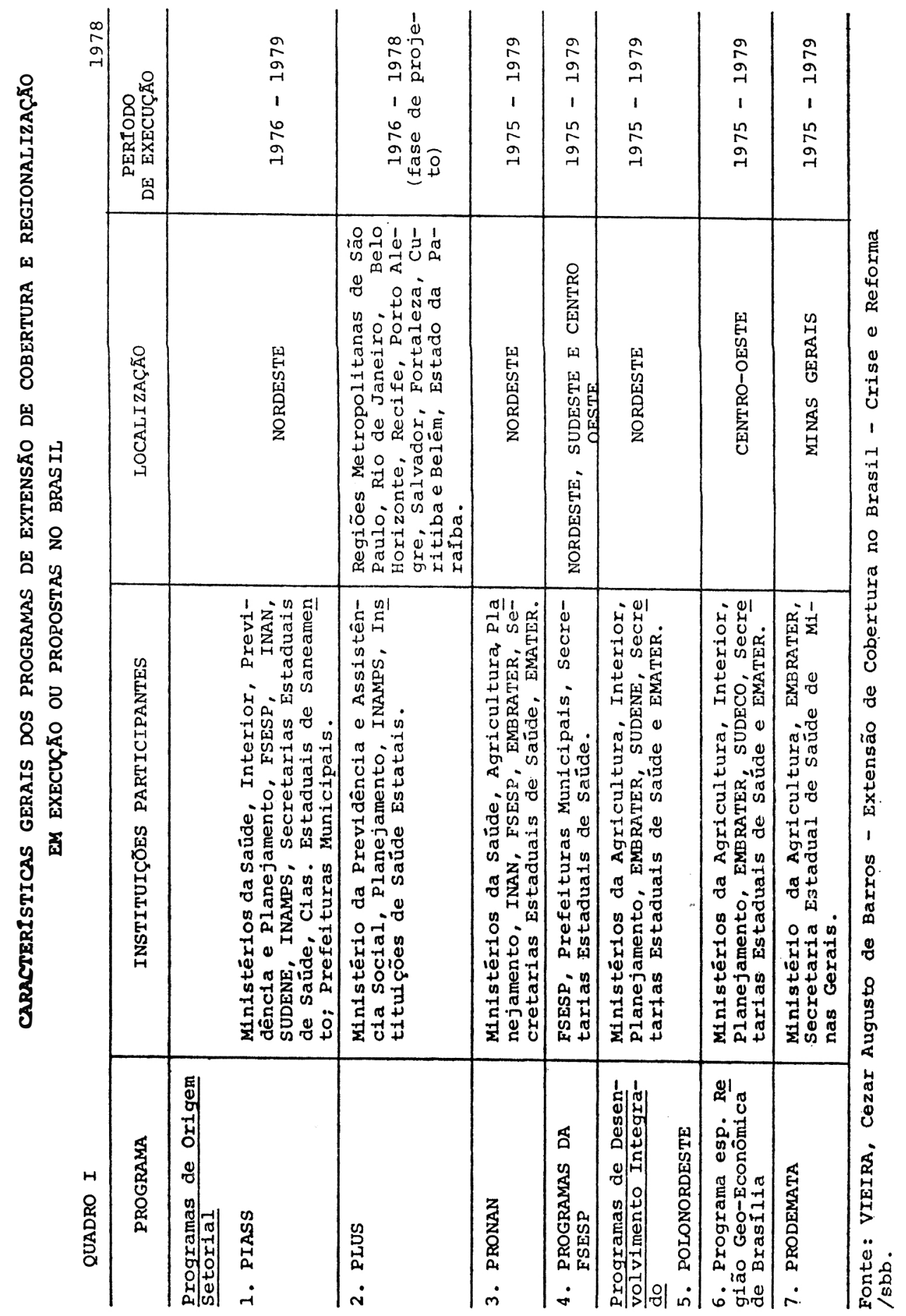


PUCU, A.S.S., THXITRA, M.C. - Aspectos do setor saúde-participaçăo do enfermeiro. Rev. Bras. Enf; DF, 32 : 375-384, 1979.

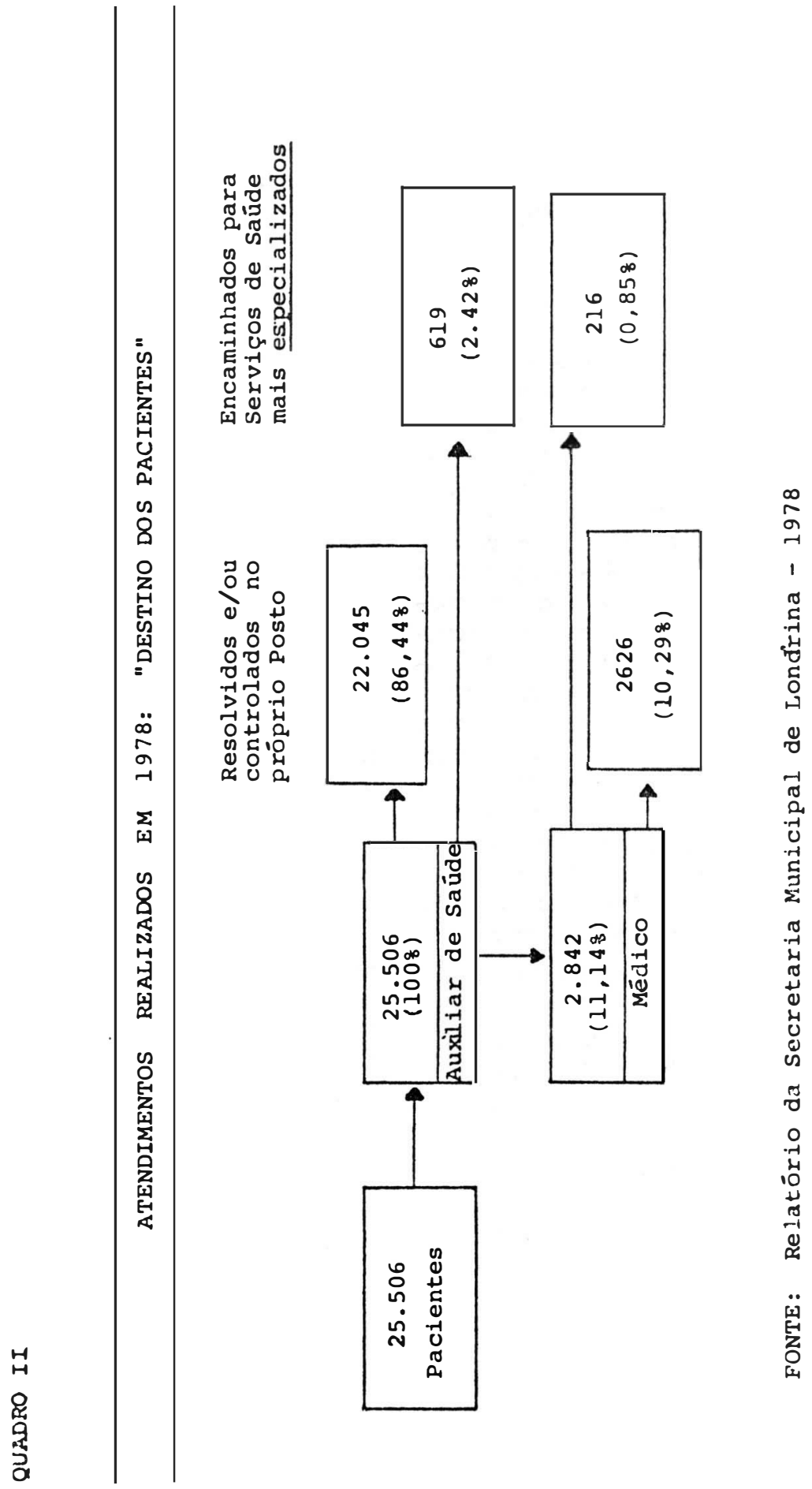


PUCU, A.S.S., TMIXaIRA, M.C. - Aspectos do setor saúde-participaçăo do enfermeiro. Rov. Bras. Enf.; DF, 32 : 375-384, 1979.

\section{III - FORMAÇĀO TEÓRICO-PRATICA DO ENFERMEIRO FACE AO DESENVOLVIMENTO DE NOVOS MODELOS ASSISTENCIAIS}

A implantação do Sistema Nacional de Saúde (Lei n.o 6.229/75) e a adoção de novos modelos para o setor, refletem sobre o sistema formador a necessidade de preparar pessoal em seus vários níveis: superior, técnico e auxiliar, adequado às atividades básicas a serem desenvolvidas. Sem essa necessária adequação existe o risco de uma distorção, pois somente os profissionais com formação especializada na área de saúde pública e/ou experiência prévia, seriam absorvidos nesta área de trabalho. Fato que ocorre na fase atual em relação aos profissionais de nível superior, o que contraria os objetivos desses modelos em relação ao emprego de recursos humanos. Havendo, portanto, necessidade de preparar pessoal com embasamento teórico-prático mínimo, para atuar nas área de execução e supervisão a nível local e regional. Evitandose, desta forma, a especialização e conseqüentemente a dissociação, entre o perfil profissional necessário ao sistema de prestação de serviços e o definido, e/ou oferecido pelo sistema formador.

Onde esses modelos têm sido desenvolvidos, sua operacionalização exige profissionais com visão, menos dirigida ao atendimento do doente e que não situem o hospital como elemento central do sistema de saúde. Este aspecto é de particular importância no caso do Enfermeiro por sua significativa participação em todos os níveis e destacadamente na preparação, supervisão e orientação do pessoal de nivel técnico e auxiliar. Tem-se como exemplos: os programas das Secretarias Municipals de Londrina, Campinas e Niterói; das Secretarias Estaduais do Nordeste em convênio com o PIASS, assim como, as propostas dos Planos diretores do PLUS.
O estudo dos programas citados, permite formular uma sintese das açōes do modelo alternativo a serem executados a nível local e regional, a seguir:

- Assistência ao adulto;

- Assistência à gestante, puérpera, recém-nato e à criança;

- Saneamento básico do meio;

- Controle e notificação de doenças transmissíveis;

- Controle, treinamento e supervisão de parteiras;

- Fornecimento de medicamentos;

- Coleta e registro de dados bioestatísticos e de produção;

- Assistência odontológica preventiva e restauradora;

- Educação para a saúde;

- Programa de nutrição;

- Exames loboratoriais;

- Hospitalização (segundo níveis de referência).

Instituições diversas realizam programas próprios tendo como básicas estas ações e a delegação de funções ao pessoal auxiliar. Em razão destes fatos, o enfermeiro deverá receber formação a nível de graduação, que o capacite para atuar enquanto membro da equipe de saúde e na área específica das atividades de enfermagem.

A grande questão levantada é: de que modo a formação teórico-prática do enfermeiro, no momento atual, permite-lhe de forma dinâmica, o desempenho das funções e atividades exigidas para a operacionalização do modelo?

No campo da enfermagem verificase uma preocupação com o estudo e o engajamento na reestruturação do setor saúde, tendo a área docente em nível de graduação e habilitação buscado reformular currículos e programas de curso.

Considerando-se as estruturas de serviços propostos pelos modelos, as Escolas de Enfermagem têm como impasse a solicitação de mão-de-obra por parte do mercado de trabalho, em desacordo com a filosofia dos novos modelos assis- 
PUCƯ, A.S.S., TMXİRA, M.C. - Aspectos do setor saúde-participaçáo do enfermeiro.

Rev. Bras. Enf.; DF, 32 : 375-384, 1979.

tenciais. Desse modo, torna-se difícil adequar práticas novas aos campos de estágio oferecidos, em sua maioria em Instituições, nas quais os serviços são organizados de "forma tradicional".

$\mathrm{Na}$ maioria das Instituiçōes as diretrizes e funções diferem das novas propostas, e o desenvolvimento do exercício técnico profissional do enfermeiro é limitado e cerceado em algumas atividades, tais como: consulta de enfermagem, realização de partos, solicitação de exames simples, controle do crescimento e desenvolvimento e outras práticas imprescindíveis, sob o enfoque dos novos modelos propostos . (Quadro III) .

Estes aspectos apresentam contradiçōes que oferecem sérias dificuldades à área docente de enfermagem. Por um lado, um novo mercado propondo que o profissional seja capaz de treinar, supersionar e orientar o pessoal auxiliar, para realização de atividades, quando a maioria das instituições assistenciais do setor, não admite sequer que tais atividades sejam executadas pelo próprio enfermeiro.

Mesmo considerando-se a problemática acima enfocada, alguns aspectos são ainda pouco discutidos nas instituiçōes de formação do enfermeiro, tais como: maior questionamento e estudo acerca dos programas e projetos atuais; sua importância do ponto-de-vista social; as implicações no campo do exercício profissional e a necessidade do enfermeiro lutar por maior participacão em todas as fases dos programas. Impōe-se que, dentro das instituições de ensino, estas discussões sejam analisadas de forma mais critica e profunda de tal modo, que possam redundar em modificações do enfoque quanto às formas de assistência prestada à população, e na busca de campos de estágio alternativos. Favorecendo, assim, a mudança de comportamento do enfermeiro, visando a oportunidade de ocupar uma nova posição na equipe de saúde, através de visão mais adequada da realidade sócio-econômica e da necessidade de participação em açōes integradas.

\section{IV - ATUAÇAOO DO PROFISSIONAL NOS PROGRAMAS E PROJETOS}

Analisando os programas e projetos tanto os operacionalizados quanto os ainda em fase de proposta teórica, verifica-se que a base das atividades a serem desenvolvidas, são, em sua maioria, açōes precípuas de enfermagem a serem executadas por pessoal auxiliar, exigindo, portanto, a presença do enfermeiro para treinamento e supervisão dessas ações.

Além deste fato constata-se que o mesmo é um profissional básico da equipe de saúde e sempre foi sensivel às atividades preventivas que visassem a melhoria da qualidade de saúde da população.

No projeto de criação do PIASS, apesar do enfermeiro não constar como profissional integrante da equipe, embora seja citada a presença do técnico e do auxiliar de enfgermagem, a necessidade daquele profissional se impôs. Hoje ele integra a equipe tanto a nível central na planejamento e normatização, como também, a nível regional no treinamento e supervisão.

Este exemplo serve para llustrar uma distorção, a nível das decisōes políticas e técnicas, quando é feita a colocação teórica de uma nova perspectiva de trabalho onde se enfoca a multiprofissionalidade. Outro aspecto a ser destacado é que a presença do enfermeiro, nas equipes responsáveis pela implementação desses programas, ainda é pouco significativa e mesmo reduzida, considerando-se que a maioria das ações de saúde concernentes ao modelo de assistência primária, são tipicamente, de enfermagem. Portanto, em se tratando quer do aspecto técnico, quer do aspecto legal, não pode este profissional ser prescindido e/ou substituido. 
PUCU, A.S.S., THXIRA, M.C. - Aspectos do setor saúde-participaçăo do enfermeiro. Rev. Bras. Ene; DF, 32 : 375-384, 1979.

\begin{tabular}{|c|c|c|c|c|c|c|c|}
\hline 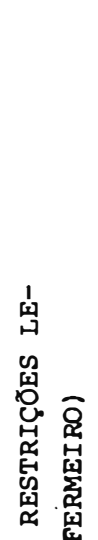 & 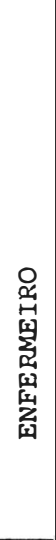 & 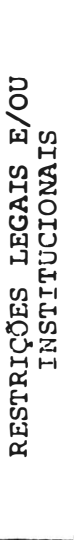 & 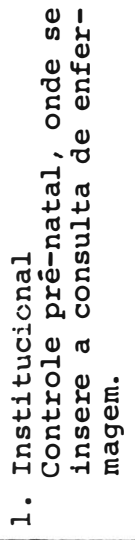 & 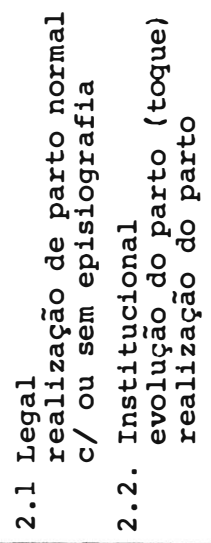 & 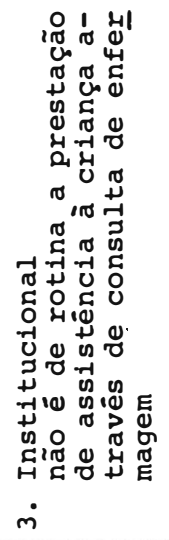 & 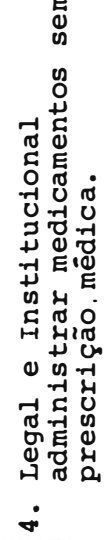 & \\
\hline 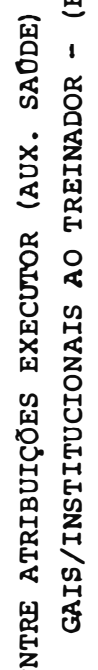 & $\begin{array}{l}\text { 四 } \\
\text { 发 } \\
\text { 四 }\end{array}$ & 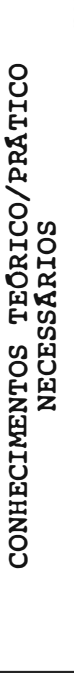 & 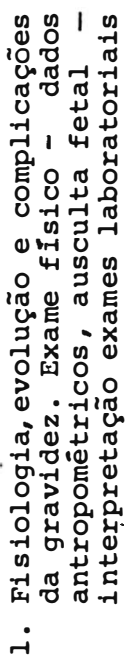 & 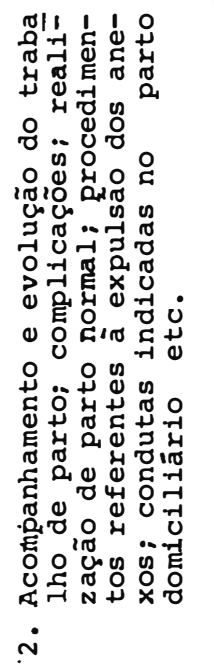 & 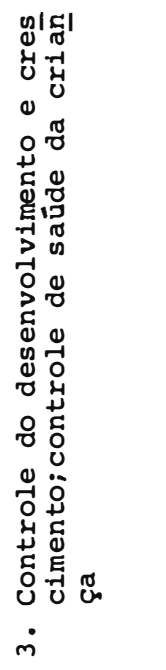 & 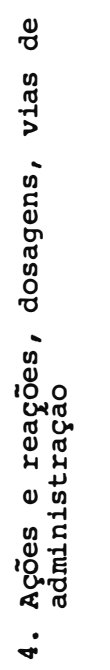 & 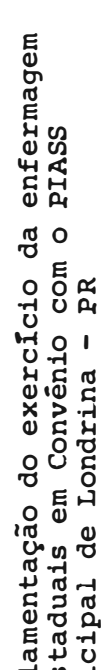 \\
\hline 怘 & 䏍 & 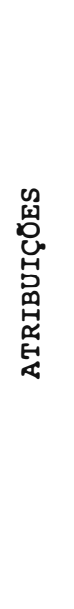 & 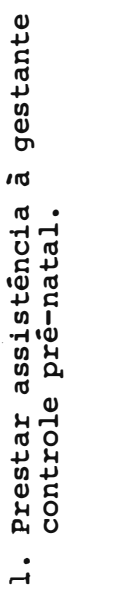 & 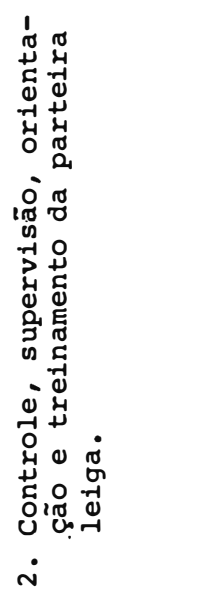 & 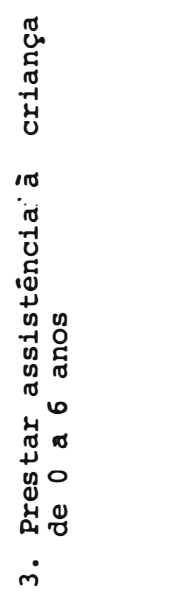 & 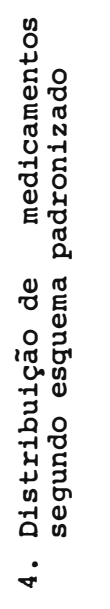 & 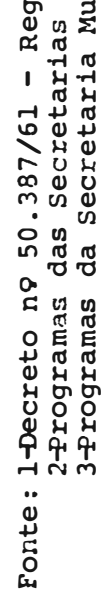 \\
\hline
\end{tabular}


PUCU, A.S.S., TMXIIRA, M.C. - Aspectos do setor saúde-participaçăo do enfermeiro.

Rov. Bras. Enf.; DF, 32 : 375-384, 1979.

Não se trata de uma visão pretenciosa, de apropriação das açōes de saúde como exclusividade de uma categoria profissional, como é ainda enfatizado quer a nível institucional, quer a nível social o binômio médico/saúde; mas sim, de considerar a potencialidade e o espaço de competência espcífica de cada profissional dentro da equipe.

Assim como é impartante que se abra uma perspectiva de maior participação, não só do enfermeiro, como de outros profissionais da equipe de saúde, no programas de extensão de cobertura e/ou regionalização, tamb;m se faz necessário:

1 - que sejam modificadas as diretrizes do sistema formador visando corrigir, entre outras, as distorções da relação quantitativa da equipe de saúde;

2 - na medida em que os programas visam ações integradas com o objetivo final de prestação de assistência à saúde, uma nova relação interprofissional se impōe. E, para que a melhoria desta interrelação se proceda, é imprescindível que os profissionais se dispam da nenecessidade de mistificar o seu papel profissional e social, estabelecidos segundo moldes ultrapassados e elitistas, que não mais se coadunam com a perspectiva dos novos modelos assistenciais do setor saúde, integrantes $\mathrm{e}$ resultantes de uma dada realidade sócio-econômica e cultural.

\section{V - LEGISLAÇAOO PROFISSIONAL ANTE AS ATIVIDADES PROPOSTAS}

O Decreto n. ${ }^{\circ} 50.387$, de 28 de março de 1961, que regulamento o exercício da enfermagem, diz no seu artigo 11, parágrafo único:

"E da responsabilidade da obstetriz e da parteira: a) prestar assistência de enfermagem obstétrica à mulher no ciclográvido puerperal em domicilio ou no hospital;

b) acompanhar o parto e o puerpério normais, limitando-se aos cuidados indispensáveis à parturiente $\mathrm{e}$ ao recém-nascido."

O ante-projeto do Conselho Federal de Enfermagem COFEN, propõe uma nova lei de regulamentação do exercício da enfermagem, também, no parágrafo único, do seu artigo n. ${ }^{\circ} 11$, menciona:

"As enfermeiras obstétricas ou obstetrizes referidas no artigo 6.0. incumbe ainda:

a) assistência ao parto normal;

b) identificação das distócias obstétricas e tomadas de providências até a chegada do méaiico;

c) realização de episiotomia, episiorrafia e aplicação de anestesia local, quando necessária."

Como se pode observar, tanto na lei em vigor quanto no ante-projeto, é permitido apenas à parteira, à obstetriz e à enfermeira obstétrica prestar assistência ao parto. No entanto, quando se analisam as atividades proposta para 0 "Atendimento Polivalente" ou "Auxiliar de Saúde" nos programas de extensão de cobertura, em execução nas secretarias de Saúde de Londrina e dos Estados do Nordeste em convênio com o PIASS, constatam-se alguns pontos altamente conflitantes com a própria legislação vigente, 0 que se pode notar no Quadro III.

A legislação que nega ao enfermeiro graduado a possibilidade de prestar assistência ao parto, obriga-o a ensinar aos Auxiliares de Saúde para atuar em programas em que este deverá ter a seu cargo a orientação e supervisão da parteira leiga, além de admitir oficiosamente a esta última a realizaçāo do parto. Para que o enfermeiro possa participar desses programas, necessário se faz que a legislação the assegure o di- 
PUCU, A.S.S., TEXXIRA, M.C. - Aspectos do setor saúde-participaçáo do enfermeiro.

Rov. Bras. Enf.; DF, 32 : 375-384, 1979.

reito de realizar o parto normal, fato que viria pressionar o sistema formador no sentido de sua capacitação.

Outro ponto conflitante é o que diz respeito ao artigo 15, alínea "b": "é vedado a todo pessoal de enfermagem administrar medicamentos sem prescrição médica, salvo em casos de extrema urgência...". Quando das atribuições do Atendente, segundo diversos programas, consta "distribuiçāo de medicamentos segundo esquema padronizado". Considerando-se discutível ser esta uma forma de prescrição médica.

No papel de treinador e supervisor do pessoal auxiliar, o enfermeiro necessita do domínio de algumas outras técnicas que, embora não entrem em choque com a legislação, o seu desempenho não lhe é familiar, como por exemplo a execução de exames laboratoriais simples.

Alguns fatores podem ser levantados como responsáveis pelos pontos contraditórios acima referidos, tais como:

- As limitaçōes do sistema formador em preparar pessoal com perfil profissional adequado às reais necessidades da população, que são explicitadas e coerentes nos novos modelos;

- A limitação da legislação vigente que por sua vez é conseqüên- cia das pressões sociais que limitam o exercício profissional do enfermeiro e sua posição no mercado de trabalho.

\section{IV - CONCLUSĀO}

A grande discussão não é questionar os programas considerando que do ponto-de-vista social estes constituem as propostas mais conseqüentes do momento. São propostas alternativas apresentadas como respostas à reformulação do setor de saúde, há muito em crise.

Este modelos no contexto sócioeconômico e cultural do país podem significar e contribuir para a methoria real do nível de saúde da população, devendo, portanto, serem defendidas e apoiadas por todos os profissionais da área.

A grande discussão proposta, é sim, analisar as causas sociais, institucionais, legais, as diretrizes que orientam a formação profíssional e que estão impedindo e/ou bloqueando a maior participação do enfermeiro na execução das atividades. Este, como profissional e antes de tudo, membro de uma determinada sociedade, não pode portanto, se alienar do contexto social e econômico do país e de como se insere a questão saúde no mesmo.

\section{BIBLIOGRAFIA}

1. BRASIL - Anais da V Conferência de Saúde - Brasilia - 1975.

2. BRASIL - Anais da VI Conferência Nacional de Saúde - Brasilia 1977.

3. BRASIL - II Plano Nacional de Desenvolvimento - Brasilia - 1974.

4. Ministério da Saúde OPAS/OMS Padrões Mínimos de Assistência de Enfermagem à Comunidade Brasilia - 1977.

5. PIASS/PPREPS - Avalação do Desenvolvimento de Recursos Humanos de Nível Elementar para Módulo Básicos (Atendente de Saúde Pública) - Brasilia - 1979.

6. PIASS - Exposiçåo de Motivos e De- creto dë Criaçæ̃o - Brasilia 1978.

7. PLUS - Documentos do GT/PLUS Convênio SEPLAN/MPAS - Rio de Janeiro - 1975/1978.

8. Secretaria Municipal de Saúde - Relatório Anual - Londrina - 1978.

9. Secretaria Municipal de Saúde - Programa de Implantação do Sistema Municipal de Saúde - Londrina - 1978.

10. VIETRA, Cezar Augusto de Barros Extensão de Cobertura no Brasil, Crise e Reforma do Sistema de Saúde, XXX Congresso Brasileiro de Enfermagem, ABEN - Santa Catarina - 1978 